\title{
PENGARUH KEPEMIMPINAN TERHADAP KINERJA KARYAWAN PADA DINAS PEMDAM KEBAKARAN DAN PENYELAMATAN DI SERANG, BANTEN
}

\author{
${ }^{*}$ Didi Wandi, ${ }^{2}$ Sucihati, ${ }^{3}$ Fuadi \\ Sekolah Tinggi Ilmu Ekonomi Banten, Serang, Banten, Indonesia \\ *didi.wandi81@gmail.com
}

\begin{abstract}
Abstrak
Penelitian ini bertujuan untuk mengetahui pengaruh kepemimpinan terhadap kinerja karyawan pada Dinas Pemdam Kebakaran Dan Penyelamatan di Serang, Banten. Metode yang digunakan adalah explanatory research dengan sampel sebanyak 100 responden. Teknik analisis menggunakan analisis statistik dengan pengujian regresi, korelasi, determinasi dan uji hipotesis. Hasil penelitian ini variabel kepemimpinan diperoleh nilai rata-rata skor sebesar 3,417 dengan kriteria baik. Variabel kinerja karyawan diperoleh nilai rata-rata skor sebesar 3,841 dengan kriteria baik. Kepemimpinan berpengaruh positif dan signifikan terhadap kinerja karyawan dengan nilai persamaan regresi $Y=9,266+0,853 X$, dan nilai koefisien korelasi 0,773 atau memiliki tingkat hubungan yang kuat dengan nilai determinasi 59,8\%. Uji hipotesis diperoleh signifikansi 0,000<0,05.
\end{abstract}

Kata Kunci: Kepemimpinan, Kinerja Karyawan.

This study aims to determine the effect of leadership on employee performance at the Fire and Rescue Service in Serang, Banten. The method used is explanatory research with a sample of 100 respondents. The analysis technique uses statistical analysis with regression, correlation, determination and hypothesis testing. The results of this study of leadership variables obtained an average score of 3,417 with good criteria. Employee performance variable obtained an average score of 3.841 with good criteria. Leadership has a positive and significant effect on employee performance with a regression equation value of $Y=9.266+0.853 X$, and a correlation coefficient value of 0.773 or has a strong relationship with a determination value of $59.8 \%$. Hypothesis testing obtained a significance of $0.000<0.05$.

Keywords: Leadership, Employee Performance. 


\section{PENDAHULUAN}

Sumber daya manusia (SDM) merupakan salah satu faktor kunci dalam reformasi ekonomi, yakni bagaimana menciptakan SDM yang berkualitas dan memiliki keterampilan serta berdaya saing tinggi dalam persaingan global. Manusia selalu berkembang aktif dan dominan dalam setiap kegiatan organisasi, karena manusia menjadi perencana, pelaku, dan penentu terwujudnya tujuan organisasi. Tujuan tidak mungkin terwujud tanpa peran aktif pegawai meskipun alat-alat yang dipergunakan canggih. Alat-alat canggih yang dimiliki tidak ada manfaatnya jika peran aktif pegawai tidak diikutsertakan. Mengatur pegawai adalah sulit dan kompleks, karena mereka mempunyai pikiran, perasaan, status, keinginan, dan latar belakang yang heterogen yang dibawa kedalam organisasi, maka dari itu peran kepemimpinan yang efektif sangatlah penting.

Agar perusahaan mampu terus bertahan dan bersaing, dominasi teknologi saja tidak cukup jika tidak ditunjang oleh SDM yang handal, sehingga investasi dalam sumber daya ekonomi yang paling berharga, yaitu SDM tidak dapat ditunda lagi, dari sudut manajemen, seorang pemimpin harus mampu menetapkan tujuan yang hendak dicapai oleh organisasi atau perusahaan, dalam konteks ini seorang pemimpn harus mampu merancang teknik dan strategi yang tepat. Selain mampu membuat teknik dan strategi yang jitu, seorang pemimpin juga dituntut untuk mampu mengambil keputusan yang cepat dan tepat. Sebab, terlambat dalam mengambil keputusan dapat merugikan organisasi, demikian juga salah dalam mengambil keputusan tentunya harus berhadapan dengan sejumlah konsekuensi seperti dana, waktu, dan tenaga. Apabila seorang pemimpin ingin mencapai tujuannya dengan efektif, maka harus mempunyai kewenangan untuk memimpin para bawahannyadalam usaha mencapai tujuan tersebut.

Pada sebuah organisasi pemerintahan, kesuksesan atau kegagalan dalam pelaksanaan tugas dan penyelenggaraan pemerintahan, dipengaruhi oleh kepemimpinan, melalui kepemimpinan dan di dukung oleh kapasitas organisasi pemerintahan yang memadai, maka penyelenggaraan tata pemerintahan yang baik (Good Govermance) akan terwujud, sebaliknya kelemahan kepemimpinan merupakan salah satu sebab keruntuhan kinerja birokrasi di Indonesia. Istianto (2009: 2).

Kepemimpinan adalah cara seorang pemimpin mempengaruhi perilaku bawahan agar mau bekerjasama dan bekerja secara produktif untuk mencapai tujuan organisasi, Malayu Hasibuan (2010: 67). Menurut Robbins (2010) Kepemimpinan adalah kemampuan untuk mempengaruhi suatu kelompok kearah suatu tujuan. Kepemimpinan adalah pengaruh antara pribadi yang dijalankan dalam situasi tertentu serta diarahkan melalui proses komunikasi kearah pencapaian satu atau beberapa tujuan tersebut.

Kepemimpinan (leadership) dapat dikatakan sebagai cara dari seorang pemimpin (leader) dalam mengarahkan, mendorong dan mengatur seluruh unsurunsur di dalam kelompok atau organisasinya untuk mencapai suatu tujuan organisasi yang diinginkan sehingga menghasilkan kinerja pegawai yang maksimal. Dengan meningkatnya kinerja pegawai berarti tercapainya hasil kerja seseorang atau pegawai dalam mewujudkan organisasi, maka harus adanya komunikasi antara atasan dan bawahan yang optimal, kerja sama antar pegawai dalam bekerja, harus adanya motivasi dari atasan yang diberikan kebawahan dan harus optimalnya kinerja pegawai dan rasa tanggung jawab pegawai.

Pemimpin (Leader $=$ Head) adalah seorang pemimpin yang dalam melaksanakan kepemimpinannya hanya atas kekuasaan (power) yang dimilikinya. Falsafah kepemimpinannya bahwa bawahan adalah untuk pemimpin. Pemimpin menganggap dirinya paling berkuasa, paling cakap, sedangkan bawahan dianggap hanya pelaksana 
keputusan-keputusannya saja. Pelaksanaan kepemimpinannya dengan memberikan instruksi/ perintah-perintah, ancaman sangsi, dan pengawasan yang ketat. Pelaksanaan kepemimpinannya cenderung menumbuhkan kepercayaan, partisipasi, loyalitas, dan internal motivasi para bawahan dengan cara persuasif. Hal ini sesuai akan diperoleh karena kecakapan, kemampuan, dan perilakunya.

Menurut Sri Rahmi (2014: 19) kepemimpinan merupakan suatu kemampuan seseorang pemimpin untuk mempengaruhi, memotivasi, dan memungkinkan orang lain untuk berkontribusi terhadap efektivitas dan keberhasilan organisasi. Artinya sisi keefektifan sumberdaya organisasi dalam mencapai tujuan organisasi yang perlu dicapai secara efektif, jadi dapat dikatakan kepemimpinan yang efektif ialah yang dapat mempengaruhi orang lain sehingga mereka termotivasi untuk memberikan kontribusi pada pencapaian kelompok.

Menurut Hasibuan (2011:

Kepemimpinan adalah seseorang dengan wewenang kepemimpinannya mengarahkan bawahannya untuk mengerjakan sebagian dari pekerjaannya dalam mencapai tujuan. Jadi pemimpin harus mempunyai bawahan, harus membagi pekerjaannya dan harus tetap bertanggung jawab terhadap pekerjaan tersebut.

Menurut Robert Tanembaum (2011: 43) Kepemimpinan adalah mereka yang menggunakan wewenang untuk mengorganisasi, mengarahkan, mengontrol para bawahan yang bertanggung jawab, supaya semua bagian pekerjaan dikoordinasi demi pencapaian tujuan perusahaan.

Dalam organisasi kinerja adalah jawaban dari berhasilnya atau tidaknya tujuan organisasi yang telah ditetapkan. Pemimpin perusahaan atau manajer seringkali mengabaikan dan tidak memperhatikan masalah kinerja kecuali kalau sudah amat buruk, terlalu sering tidak mengetahui betapa buruknya kinerja telah merosot sehingga perusahaan atau instansi menghadapi krisis yang serius.

Kinerja harus dilakukan dengan efektif dan efisien yang artinya dalam melaksanakan pekerjaan organisasi dengan menggunakan sumberdaya organisasi itu harus dilakukan dengan cermat dan teliti agar tidak terjadi pemborosn. Kinerja yang baik dan berkualitas bisa berakhibat baik juga bukan hanya dari perusahaan atau instansi tersebut tetapi bagi karyawan atau pegawi dari perusahaan itu sendiri, bahkan dapat dirasakan oleh masyarakat luas.

Menurut Moeheriono dalam $\mathrm{M}$. Ma'ruf Abdullah (2014: 3) Kinerja atau performance merupakan gambaran mengenai tingkat pencapaian pelaksanaan suatu program kegiatan atau kebijakan dalam mewujudkan sasaran, tujuan, visi dan misi organisasi yang dituangkan melalui perencanaan strategis atau suatu organisasi.

Terdapat Pedoman Aperatur Negara, Pedoman tersebut merupakan pedoman dalam melaksanakan kinerja kerja aparatur negara pada lingkungan instansi atau lembaga masing-masing, untuk menumbuhkan dan meningkatkan semangat kerja, disiplin dan tanggung jawab moral aparaturnya secara terusmenerus dan konsisten, sesuai dengan tugas dan fungsi masing-masing.

Menurut Wirawan (2009: 5), kinerja adalah keluaran yang dihasilkan oleh fungsi-fungsi atau indikator-indikator suatu pekerjaan atau suatu profesi dalam waktu tertentu.

Menurut Irham Fahmi (2013: 2), kinerja adalah hasil yang diperoleh suatu organisasi baik organisasi tersebut bersifat profit oriented dan non profit oriented yang dihasilkan selama satu periode tertentu. Definisi dari kinerja merupakan suatu hasil kerja yang dihasilkan oleh seorang pegawai dalam melaksanakan tanggung jawabnya di dalam suatu organisasi yang dilakukan dalam suatu periode tertentu.

Pentingnya kinerja pegawai Dinas Pemadam Kebakaran Dan Penyelamatan adalah proses yang digunakan untuk memberikan manfaat pekerjaan yang baik jika dikerjakan dengan benar, dan 
mengukur sejauh mana kinerja pegawai Dinas Pemadam Kebakaran Dan Penyelamatan, hal ini memberikan manfaat yang penting bagi para pegawai maupun pimpinan dalam suatu organisasi, dan hasil evaluasi kinerja dapat dilakukan untuk menentukan tindakan yang tepat. Dan pentingnya kinerja pegawai perlu dicermati untuk mengetahui kemampuan pegawai, penerimaan tujuan pegawai, tingkat tujuan yang dicapai, dan interaksi antara tujuan dan kemampuan para pegawai dalam perusahaan dimana masing-masing elemen tersebut berpengaruh terhadap kinerja seseorang.

Penelitian ini bertujuan mengetahui kepemimpinan yang berpengaruh terhadap kinerja kerja Dinas Pemadam Kebakaran Dan Penyelamatan Serang Banten. Kepemimpinan yang ada di Dinas Pemadam Kebakaran Dan Penyelamatan Serang Banten dipimpin oleh Kepala Pimpinan yang membawahi 100 orang pegawai membutuhkan kepemimpinan yang baik sehingga Dinas Pemadam Kebakaran Dan Penyelamatan Serang Banten dapat menciptakan pelayanan yang maksimal kepada masyarakat yang ada di wilayah tersebut.

Sehubungan dengan hal tersebut diatas, maka penulis tertarik untuk mengamati, melihat dan melakukan penelitian tentang bagaimana pengaruh kepemimpinan terhadap kinerja pegawai pada Dinas Kebakaran Dan Penyelamatan Serang Banten, dan dari uraian tersebut penulis akan melakukan penelitian dengan judul "Pengaruh Kepemimpinan Terhadap Kinerja Pegawai Pada Dinas Pemdam Kebakaran Dan Penyelamatan Di Serang Banten".

\section{TINJAUAN PUSTAKA}

\section{Kepemimpinan}

Yang dimaksud dengan Kepemimpian dalam penelitian ini adalah norma perilaku yang digunakan oleh seseorang pada saat orang tersebut berusaha mempengaruhi para bawahannya. (Hasibuan, 2011: 205).

\section{Kinerja Karyawan}

Kinerja dalam penelitian ini adalah prestasi kerja yang merupakan hasil dari implementasi rencana kerja yang dibuat oleh suatu institusi yang dilaksanakan oleh pimpinan dan karyawan atau pegawai (MSDM) yang bekerja di institusi itu. (M. Ma'ruf Abdullah, 2014: 2).

\section{METODE PENELITIAN}

\section{Populasi}

Populasi dalam penelitian ini berjumlah 100 responden Dinas Pemdam Kebakaran Dan Penyelamatan di Serang, Banten

2. Sampel

Teknik pengambilan sampling dalam penelitian ini adalah sampel jenuh, dimana semua anggota populasi dijadikan sebagai sampel. Dengan demikian sampel dalam penelitian ini sampel yang digunakan berjumlah 100 responden.

3. Jenis Penelitian

Jenis penelitian yang dipakai adalah asosiatif, dimana tujuannya adalah untuk mengetahui atau mencari keterhubungan antara variabel independen terhadap variabel dependennya

4. Metode Analisis Data

Dalam menganalisis data digunakan uji validitas, uji reliabilitas, analisis regresi linier sederhana, analisis koefisien korelasi, analisis koefisien determinasi dan pengujian hipotesis.

\section{HASIL PENELITIAN}

\section{Analisis Deskriptif}

Pada pengujian ini digunakan untuk mengetahui skor minimum dan maksimum skor tertinggi, ratting score dan standar deviasi dari masing-masing variabel. Adapun hasilnya sebagai berikut: 
Tabel 1. Hasil Analisis Descriptive Statistics

Descriptive Statistics

$\mathrm{N}$ Minimum Maximum Mean Std. Deviation

\begin{tabular}{|l|r|r|r|r|r|}
\hline Kepemimpinan $(\mathrm{X})$ & 100 & 28 & 44 & 34.17 & 3.843 \\
\hline Kinerja Karyawan (Y) & 100 & 29 & 49 & 38.41 & 4.238 \\
\hline Valid N (listwise) & 100 & & & & \\
\hline
\end{tabular}

Kepemimpinan diperoleh varians minimum sebesar 28 dan varians maximum 44 dengan ratting score sebesar 3,417 dengan standar deviasi 3,843. Skor ini termasuk pada rentang sakala 3,40 4,19 dengan kriteria baik atau setuju.

Kinerja karyawan diperoleh varians minimum sebesar 29 dan varians maximum 49 dengan ratting score sebesar 3,841 dengan standar deviasi 4,238. Skor ini termasuk pada rentang sakala 3,40 4,19 dengan kriteria baik atau setuju.

\section{Analisis Kuantitatif.}

Pada analisis ini dimaksudkan untuk mengetahui pengaruh variabel independen terhadap variabel dependen. Adapun hasil pengujian sebagai berikut:

\section{a. Analisis Regresi Linier Sederhana}

Uji regresi ini dimaksudkan untuk mengetahui perubahan variabel dependen jika variabel independen mengalami perubahan. Adapun hasil pengujiannya sebagai berikut:

Tabel 2. Hasil Pengujian Regresi Linier Sederhana

\section{Coefficients ${ }^{a}$}

Unstandardized

Coefficients

Standardized

\begin{tabular}{|c|c|c|c|c|c|}
\hline \multirow[b]{2}{*}{ Model } & \multicolumn{2}{|c|}{ Coefficients } & \multirow{2}{*}{$\begin{array}{c}\text { Coefficients } \\
\text { Beta }\end{array}$} & \multirow[b]{2}{*}{$\mathrm{t}$} & \multirow[b]{2}{*}{ Sig. } \\
\hline & B & Std. Error & & & \\
\hline 1 (Constant) & 9.266 & 2.428 & & 3.816 & .000 \\
\hline Kepemimpinan $(X)$ & .853 & .071 & .773 & 12.077 & .000 \\
\hline
\end{tabular}

Berdasarkan hasil pengujian pada tabel di atas, diperoleh persamaan regresi $Y=9,266+0,853 X$. Dari persamaan tersebut dijelaskan sebagai berikut:

1) Konstanta sebesar 9,266 diartikan jika kepemimpinan tidak ada, maka telah terdapat nilai kinerja karyawan sebesar 9,266 point.

2) Koefisien regresi kepemimpinan sebesar 0,853, angka ini positif artinya setiap ada peningkatan

Tabel 3. Hasil Pengujian Koefisien Korelasi Kepemimpinan Terhadap Kinerja

Karyawan.

Correlations $^{b}$

Kepemimpinan (X1) Kinerja Karyawan (Y)

\begin{tabular}{|c|c|}
\hline \multirow[t]{2}{*}{ Kepemimpinan $(\mathrm{X})$} & Pearson Correl \\
\hline & Sig. (2-tailed) \\
\hline Kinerja Karyawan $(\mathrm{Y})$ & Pearson Correl \\
\hline Sig. (2-tailed) .000 & \\
\hline
\end{tabular}

diperoleh nilai korelasi sebesar 0,773 kepemimpinan sebesar 0,853 point maka kinerja karyawan juga akan mengalami peningkatan sebesar 0,853 point.

\section{b. Analisis Koefisien Korelasi}

Analisis koefisien korelasi dimaksudkan untuk mengetahui tingkat kekuatan hubungan dari variabel independen terhadap variabel dependen. Adapun hasil pengujian sebagai berikut:

\begin{tabular}{|c|c|c|c|}
\hline & $\begin{array}{l}\text { Kary } \\
\text { Correl }\end{array}$ & $\begin{array}{l}\text { awan. } \\
\text { ations }{ }^{\mathbf{b}} \\
\text { Kepemimpinan }(X 1)\end{array}$ & Kinerja Karyawan $(\mathrm{Y})$ \\
\hline \multirow[t]{2}{*}{ Kepemimpinan $(X)$} & Pearson Correlation & 1 & $.773^{\star *}$ \\
\hline & Sig. (2-tailed) & & .000 \\
\hline inerja Karyawan $(\mathrm{Y})$ & Pearson Correlation & $.773^{\text {** }}$ & 1 \\
\hline
\end{tabular}

artinya kepemimpinan memiliki hubungan yang kuat terhadap kinerja karyawan. 
c. Analisis Koefisien Determinasi

Analisis koefisien determinasi dimaksudkan untuk mengetahui besarnya persentase pengaruh dari

Tabel 4. Hasil Pengujian Koefisien Determinasi Kepemimpinan Terhadap Kinerja

Karyawan.

Model Summary

\begin{tabular}{lr|r|r|r} 
Model & R & R Square & Adjusted R Square & Std. Error of the Estimate \\
\hline 1 & $.773^{\mathrm{a}}$ & .598 & .594 & 2.700 \\
\hline
\end{tabular}

Berdasarkan hasil pengujian diperoleh nilai determinasi sebesar 0,598 artinya kepemimpinan memiliki kontribusi pengaruh sebesar 59,8\% terhadap kinerja karyawan, sedangkan sisanya sebesar $40,2 \%$ dipengaruhi oleh faktor lain yang tidak dilakukan penelitian.

Tabel 5. Hasil Uji Hipotesis Kepemimpinan Terhadap Kinerja Karyawan. Coefficients ${ }^{a}$

Unstandardized Coefficients

\begin{tabular}{|c|c|c|c|c|c|}
\hline Model & B & Std. Error & Beta & $\mathrm{t}$ & Sig. \\
\hline 1 (Constant) & 9.266 & 2.428 & & 3.816 & .000 \\
\hline Kepemimpinan $(X)$ & .853 & .071 & .773 & 12.077 & .000 \\
\hline
\end{tabular}

Berdasarkan hasil pengujian pada tabel di atas, diperoleh nilai $\mathrm{t}$ hitung $>\mathrm{t}$ tabel atau $(12,077>1,984)$, dengan demikian hipotesis yang diajukan bahwa terdapat pengaruh yang signifikan atara kepemimpinan terhadap kinerja karyawan diterima.

\section{PEMBAHASAN HASIL PENELITIAN}

1. Kondisi Jawaban Responden Variabel Kepemimpinan

Berdasarkan jawaban responden, variabel kepemimpinan diperoleh ratting score sebesar 3,417 berada di rentang skala 3,40 - 4,19 dengan kriteria baik atau setuju.

\section{Kondisi Jawaban Responden Variabel Kinerja Karyawan}

Berdasarkan jawaban responden, variabel kinerja karyawan diperoleh ratting score sebesar 3,841 berada di rentang skala 3,40 - 4,19 dengan kriteria baik atau setuju.

\section{d. Uji Hipotesis}

Pengujian hipotesis dengan uji $t$ digunakan untuk mengetahui hipotesis mana yang diterima.

Rumusan hipotesis: Terdapat pengaruh yang signifikan kepemimpinan terhadap kinerja karyawan.
3. Pengaruh Kepemimpinan Terhadap Kinerja Karyawan

Kepemimpinan berpengaruh signifikan terhadap kinerja karyawan dengan persamaan regresi $Y=9,266+$ $0,853 \mathrm{X}$, nilai korelasi sebesar 0,773 atau memiliki hubungan yang kuat dengan kontribusi pengaruh sebesar 59,8\%. Pengujian hipotesis diperoleh nilai $\mathrm{t}$ hitung $>\mathrm{t}$ tabel atau $(12,077>1,984)$. Dengan demikian hipotesis yang diajukan bahwa terdapat berpengaruh signifikan antara kepemimpinan terhadap kinerja karyawan diterima.

\section{PENUTUP}

Kesimpulan

a. Variabel kepemimpinan diperoleh ratting score sebesar 3,417 berada di rentang skala 3,40 - 4,19 dengan kriteria baik atau setuju.

b. Variabel kinerja karyawan diperoleh ratting score sebesar 3,841 berada di rentang skala 3,40 - 4,19 dengan kriteria baik atau setuju. 
c. Kepemimpinan berpengaruh signifikan terhadap kinerja karyawan dengan persamaan regresi $\mathrm{Y}=9,266+0,853 \mathrm{X}$, nilai korelasi sebesar 0,773 atau kuat dan kontribusi pengaruh sebesar 59,8\% sedangkan sisanya sebesar $40,2 \%$ dipengaruhi faktor lain. Uji hipotesis diperoleh nilai $\mathrm{t}$ hitung $>\mathrm{t}$ tabel atau $(12,077>1,984)$.

\section{Saran}

Berdasarkan hasil kesimpulan, maka penulis memberikan saran diantaranya sebagai berikut:

a. Pemimpin hendaknya memiliki integritas yang tinggi dan mampu menjadi suritauladan kepada bawahannya sehingga menambah kepercayaan karyawannya

b. Pimpinan harus mampu mengajarkan pekerjaan yang mampu diselesaikan tepat waktu dan memenuhi kuantitas yang ditentukan sehingga mencapai target perusahaan

\section{DAFTAR PUSTAKA}

Abdullah, M (2014) Manajemen dan Evaluasi Kinerja Karyawan, Yogyakarta: Penerbit Aswaja Pressindo.

Affandi, A., Sarwani, A. S., Erlangga, H., Siagian, A. O., Purwanto, A., Effendy, A. A., ... \& Wahyitno, C. D. M. (2020). Optimization of MSMEs Empowerment in Facing Competition in the Global Market during the COVID-19 Pandemic Time. Systematic Reviews in Pharmacy, 11(11), 1506-1515.

Algifari. (2015). “Analisis Regresi untuk Bisnis dan Ekonomi". Yogyakarta: BPFE.

Arikunto, Suharsimi (2014). "Prosedur Penelitian Suatu Pendekatan Praktek". Jakarta: Rineka Cipta.

Bangun, Wilson. 2012. "Manajemen Sumber Daya Manusia". Jakarta: Erlangga

Bejo Siswanto (2013) Manajemen Tenaga Kerja Rancangan dalam Pendayagunaan dan Pengembangan Unsur Tenaga Kerja", Bandung: Sinar Baru.

Dessler, G. (2006.) Manajemen Sumber Daya Manusia (Jilid II). Jakarta: Indeks.
Edi Sutrisno (2016). Manajemen Sumber Daya Manusia. Jakarta: Prenadamedia Group.

Edi Sutrisno (2016). Manajemen Sumber Daya Manusia. Jakarta: Prenadamedia Group.

George Terry R \& Rue, Leslie W. Rue (2016) Dasar-Dasar Manajemen, Jakarta Bumi Aksara.

Gerry Dessler (2016) Human Resources Management, Prenticehall, London: International Inc.

Handoko (2016) Manajemen Personalia dan Sumberdaya Manusia. Yogyakarta: BPFE.

Hasibuan, Malayu S.P. (2016). Manajemen Sumber Daya Manusia. Edisi Revisi. Jakarta: PT Bumi Aksara.

Imam Ghozali (2017). "Aplikasi Analisis Multivariate Dengan Program SPSS". Edisi Kelima. Semarang: Badan Penerbit Undip.

Istijanto (2014) "Riset Sumber Daya Manusia". Jakarta: PT. Gramedia Pustaka

Luthans Fred (2014) Organizational Behavior, Ney York: McGraw-Hill, New York.

Mangkunegara, Prabu Anwar. (2016). Evaluasi Kinerja SDM. Cetakan ke tujuh, PT Refika Aditama: Bandung.

Muslimat, A., Muhsin, H., Wahid, H. A., Yulistiana, I., Sunarsi, D., Dewi, K., ... \& Ilham, D. (2021). Develop Technology Based Multimedia For Indonesian Teachers. Journal of Contemporary Issues in Business and Government, 27(1), 1871-1882.

Purwanti, Y. (2021). The Influence Of Digital Marketing \& Innovasion On The School Performance. Turkish Journal of Computer and Mathematics Education (TURCOMAT), 12(7), 118127.

Muslimat, A. (2021). Masa Depan Kampus Merdeka \& Merdeka Belajar: Sebuah Bunga Rampai Dosen. Bintang Visitama Publisher.

Nurjaya, N., Affandi, A., Ilham, D., Jasmani, J., \& Sunarsi, D. (2021). Pengaruh Kompetensi Sumber Daya Manusia Dan Kemampuan Pemanfaatan 
Teknologi Terhadap Kinerja Aparatur Desa Pada Kantor Kepala Desa Di Kabupaten Gunungkidul, Yogyakarta. JENIUS (Jurnal Ilmiah Manajemen Sumber Daya Manusia), 4(3), 332-346.

Robbins, P.S, \& Judge, A.T. (2003). Organizational Behavior. Jakarta: Salemba Empat.

Santoso, Singgih (2015). "Menguasai Statistik Multivariat". Jakarta: PT Elex Media Komputindo.

Sedarmayanti (2016) Manajemen Sumber Daya Manusia, Reformasi Birokrasi dan Manajemen Karyawan Negeri Sipil, Cetakan Kelima, Bandung: PT Refika Aditama.

Sudjana (2014) "Metode Statistika", Bandung: Tarsido.

Sugiyono (2017), "Metode Penelitian
Administrasi : dilengkapi dengan Metode $R \mathcal{E} D^{\prime \prime}$. Bandung: Alfabeta.

Sunarsi, D. (2017). Pengaruh Kepemimpinan Dan Budaya Organisasi terhadap Kinerja Karyawan Pada Cabang Pembantu Bank DKI Pondok Labu-Jakarta Selatan. JENIUS, 1(2), 21. (2020). The Influence of Supply Chain Strategy on Employee Performance on Small and Medium Business in Beringharjo Market, Yogyakarta-Indonesia. International Journal of Supply Chain Management, 9(5).

Veithzal Rivai (2015) Manajemen Sumber Daya Manusia Untuk Perusahaan, Jakarta: Raja Grafindo Persada.

Wibowo (2015) Manajemen Kinerja, Jakarta: PT. Raja Grafindo Persada. 